\title{
Musculoskeletal disorders and risk factors in string musicians
}

Evadio Pereira Filho ${ }^{1}$

Junior Raimundo da Silva²

\begin{abstract}
Several workers suffer from musculoskeletal disorders and the situation is even more troubling for musicians, because it is common the musical activity do not be the main source of income. This study evaluated in which extent musculoskeletal disorders and risk factors affect string musicians. Evaluations were performed within groups defined by demographic and behavioural variables. Spearman and Mann-Whitney $U$ tests were applied. A total of 97 string instrumentalists were questioned. Results indicated that bodily regions most affected were upper limbs and column. In turn, inadequate posture represented the element that most cooperated for the arise of musculoskeletal disjunctions. In general, there was no evidence to indicate that predictors of musculoskeletal disorders were similar or divergent among conglomerates. Musicians constantly suffered with complaints in upper limbs occasioned to maintain inappropriate postures during their activities.
\end{abstract}

Keywords: Musculoskeletal complaints. String instrumentalists. Risk factors
${ }^{1}$ PhD student in administration (PPGA/UFRN). Teacher of
Instituto Federal da Paraíba (IFPB), Paraíba, Brazil.
evadio.filho@gmail.com.

${ }^{2}$ Graduate in Occupational Safety (IFPB), Paraíba, Brazil. juniorraimundo95@gmail.com. 
Introduction

Musculoskeletal complaints are common symptoms in different work environments. In health organizations, for example, Carneiro, Braga and Barroso (2017) report that the lumbar region is body part most affected during activities developed by home care nurses. The authors cite seven factors as the main causers of the arise or absence of lumbar disorders: arm postures; static postures; forearm postures; bed height; furniture for arm support; job satisfaction and assistive devices (Carneiro et al., 2017). On the other hand, in schools, teachers suffer more from pathologies in the lower back, shoulders and wrist. In addition, ergonomic factors are perceived as a causative element (Cheng, Wong, Yu \& Ju, 2016). Therefore, musculoskeletal disorders depend on the environmental conditions to which the workers are submitted and the nature of their actions.

In that context, the exercise of music can be understood as a work. Thus, musicians are subject to certain risks inherent to their professional activities, as well as work diseases are peculiar. Career professionalization requires of musicians an arduous workload, including long hours of study, trainings and shows. It is customary to perform repetitive movements and to submit to instruments and places that do not conform to the physical and psychic limitations of users. As a reflex, they compromise the health, being able to develop muscular, articular and psychological disorders (Frank \& Von Mühlen, 2007). However, because it is a pleasurable activity, many musculoskeletal complaints are neglected.

For Brandfonbrener (2003), the music students had as their dogma the culture: without pain, without gain. They assimilated the arise of pain as natural consequence of the profession. The sacrifice would lead to musical perfection. Nowadays, that is recognized as a deficit strategy when it comes to musical success (Brandfonbrener, 2003). However, Brandfonbrener (2003) warns that musicians still ignore or deny, for some time, the symptoms. Other authors talk about a silence culture, in which discomfort can lead to economic losses and lack of opportunities in restricted markets (Costa \& Abrahão 2004; Stanhope \& Milanese, 2015).

Epidemiological studies have evidenced significant rates of diseases in musicians and diagnoses that affect or impede the continuity of their careers (Costa \& Abrahão, 2004). The pains became frequent symptoms. There are advances in relation to corrective measures, such as the new medical treatments that arise constantly. Nevertheless, preventive actions are implemented more slowly within the musical activities (Costa, 2005; Teixeira, Andrade, Kothe, Felden, 2015). The category of specialists in classical music (for example, orchestras) is widely referenced in theoretical-empirical essays in Brazil. Equivalent situation is found in international papers. Blanco-Piñeiro, Díaz-Pereira and Martínez (2017) put the string musicians as one of the studied subjects, especially violinists. Few Brazilian investigations focus on disorders that affect popular musicians (Moura, Fonte \& Fukujima, 2000). Popular musicians 
represent the subjects who carry out their activities with music techniques unsophisticated. In general, their academic studies are limited or even inexistent (learning method by trial and error). Many are selftaught and can be called in certain localities by street musicians. Moura et al. (2000) believe that popular musicians are affected by similar risks to classical musicians.

In addition, assessments of risk factors and musculoskeletal discomforts in musicians receive little academic attention (Lee et al. 2013). Fragelli and Günther (2009) affirm that there are academic gaps to be filled when it comes to making music activities less harmful to the health of practitioners. An aggravating factor is the growing number of sympathizers (Sousa et al., 2016).

Therefore, the present study tends to minimize this academic deficit with purpose to understand which disorders affect the string musicians and which factors potentiate the existence of these pathologies. These academic contributions will enable practitioners to adopt prevention, control and rehabilitation strategies that allow them to deal with musical routines and patterns (Kaufman-Cohen \& Ratzon, 2011). Stanhope and Milanese (2015) see as fertile field the promotion of studies capable of developing useful guidelines in relation to the improvement of the quality of life of the musicians.

This study aims to evaluate the musculoskeletal disorders and the risk factors that affect the string musicians. One key question guide the evaluation: in which extent the musculoskeletal disorders and risk factors vary with the demographic and behavioral factors associated to the musicians? The questionnaires were completed by 97 string instrumentalists. For that, Mann-Whitney $U$ and Spearman tests were used.

\section{Empirical evidence about musculoskeletal disorders}

Musculoskeletal complaints in musicians are objects of recent researches (Kok, Huisstede, Voorn, Schoones \& Nelissen, 2016) and constitute one of the main medical problems of those professionals (Heinan, 2008). Kaufman-Cohen and Ratzon (2011) report that these symptoms prevent some of them from continuing to play their instrument. Thus, several authors (Middlestadt \& Fishbein 1989; Paarup, Baelum, Holm, Manniche \& Wedderkopp, 2011; Kaufman-Cohen \& Ratzon, 2011) realized empirical researches about prevalence of musculoskeletal disorders in musicians.

Moura et al. (2000) found that the three main lesions that impact this category are musculoskeletal disorders (62\% of the subjects studied), compressive neuropathies and motor dysfunctions (18\% and 10\%, respectively). Similar findings were found by Trelha et al. (2004) and Paarup et al. (2011). These theorists identified musculoskeletal disorders as being the most present in musicians' activities. Trelha et al. (2004) cited repetitive strain injuries and work-related musculoskeletal disorders (RSI/WMSD) as highlight. In turn, Paarup et al. (2011) mentioned the pains in the upper limbs (left elbow, left hand, wrist, right shoulder, neck and upper back) as main occurrences. 
Others researches (Middlestadt \& Fishbein, 1989; Andrade \& Fonseca, 2000) also demonstrated that the body regions most sacrificed in musicians are the upper limbs. In relation to the disorders, the literature lists several. Pains and discomforts are those most cited. The studies of Middlestadt and Fishbein (1989), Trelha et al. (2004) reinforce that finding. In addition, a broad set of symptoms was recorded: tendinitis (Andrade \& Fonseca, 2000), dormancy (Andrade \& Fonseca, 2000), hearing problems (Andrade, Russo, Lima \& Oliveira, 2002; Mendes \& Morata, 2007), tremors (Costa \& Abrahão, 2004), overuse syndrome (Pederiva, 2004; Frank \& Von Mühlen, 2007; Stanhope \& Milanese, 2015), headache (Engquist, Orbaek \& Jakobsson, 2004; Amorim, Lopes, Santos \& Melo, 2008), among others. Appendix 1 shows the main musculoskeletal disorders mentioned in empirical studies.

\section{Studies that discuss risk factors}

The causes for the existence of musculoskeletal disorders are multidimensional. There are several elements that interact with each other and result in physical and psychological problems. In the music segment, the potential causes of occupational diseases (called risk factors) are diverses. Brandfonbrener (2003), for example, pointed to practice time as one of the risk factors that contribute most to the development of diseases. However, she emphasized that this is not the only. According to the author, there are others such as: practice of a new repertoire, weight of the instrument, physical conditioning of the practitioner, teaching techniques of a new teacher and size of the hand.

For Frank and Von Mühlen (2007), the peculiarities of the instrument (format, size, weight), musical technique and repertoire are aggravating. The authors emphasized that this requires of the musician an asymmetrical and non-ergonomic posture. Costa (2005) cited inadequate furniture as an item requiring extra efforts to maintain posture. The absence of adjustments in elements that make up the workstation of the musicians (chair, sheet music stand and support for the musical instrument) leads to physical overloads. Moreover, Costa (2005) reinforced that the culture of standardization is peculiar in the musical environment.

Zaza and Farewell (1997) mentioned that a number of individual characteristics are relevant for determining the development of musculoskeletal disorders. They argued that warm-up before and breaks during practice sessions can prevent the occurrence of injuries. In the same chain of thought, Kaufman-Cohen and Ratzon (2011) said that biomechanical hazards, instrument weight and working hours per week were the main predictors.

Others risk factors are evidenced in the literature and placed as responsible for developing musculoskeletal complaints in musicians. These included: type of instrument played (Middlestadt \& Fishbein, 1989; Kaufman-Cohen \& Ratzon, 2011), repetition (Andersen, Kaergaard \& Mikkelsen, 2003), conditions (temperature, lighting) in the workplace (Harkness, Macfarlane \& Nahit, 2003), sheet music 
(Costa \& Abrahão, 2004), psychological factors (Kaergaard \& Andersen, 2000), among others. However, it is noted that there is no consensus among authors about risk factors. Even though there are common factors among the communities of musicians, each one of them with their social, employment and educational characteristics. Appendix 2 presents the list of risk factors most cited in the literature.

\section{Method}

The quantitative paradigm was used in this study. For Brown (2015), quantitative research has mechanistic aspects in which the researcher conducts his work from a plan established a priori. The author emphasized that replicability is one of its main characteristics. The aim was to understand the behavior of disturbances and risk factors in different groups of musicians through mathematical models. These groups were delimited from demographic (age and gender) and behavioral (study time per day, time of profession, category, dominant hand, type of instrument and stretching) variables. The methodological design adopted is shown in Figure 1.

Figure 1 - Methodological design

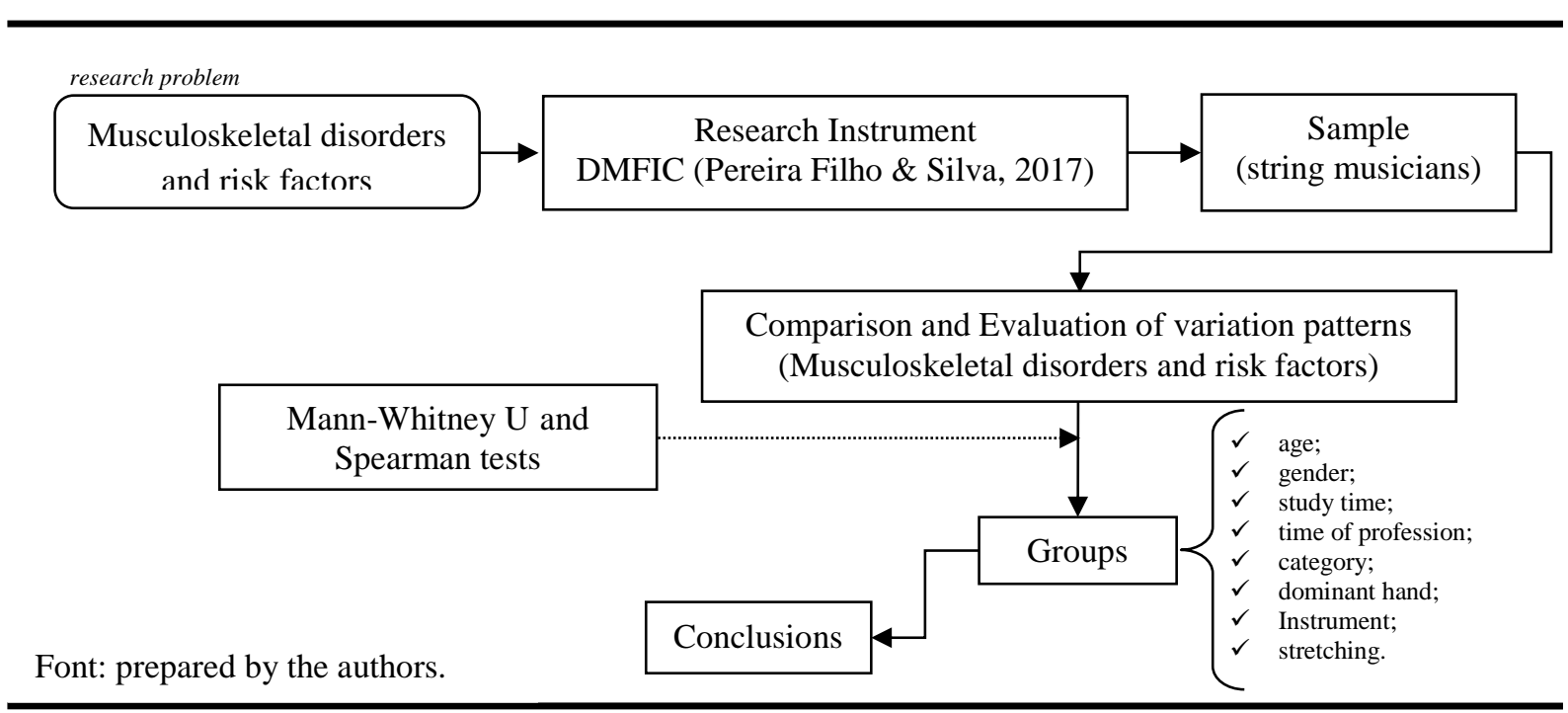

\section{Instrument}

Data were collected from the instrument named DMFIC. This framework was developed by Pereira Filho and Silva (2017) with the purpose of evaluating the risk factors and musculoskeletal disorders associated to musicians' activity. Four sections formed the research instrument, totaling fortyfour sentences. The first section had eleven questions regarding respondents' demographic and behavioral aspects. The following two sections addressed the prevalence of disorders. Each one of them 
was composed of ten questions that had the same content, but were evaluated from different parameters. The second section investigated frequency and the third focused on the intensity of each disorder. The fourth section investigated the contribution of risk factors for the appearance of musculoskeletal disorders in the perception of respondents. This module contained thirteen assertions. In the last three sections, an ordinal scale of eleven points was employed.

\section{Sample}

The DMFIC instrument was applied with professional and amateur musicians. The selection of the participants obeyed criteria of convenience and opportunity. This procedure is justified by the absence of official information on quantity, residence and contacts of the musicians within territorial space analyzed. In addition, the researchers chose to incorporate only musicians with activities in sertão of Paraíba and playing certain instruments (six string acoustic guitar, six string electric guitar and four string electric bass). Assuming 40,000 musicians (four percent of the local population), the sample calculation reached ninety six individuals (95\% confidence and 10\% error). One hundred and three questionnaires were applied, with six exclusions. When we verified that the subject was cognitively unable to evaluate at least one of the sentences, the questionnaires were discarded. Ninety-seven questionnaires were considered valid.

\section{Data Collection and Analysis}

The data collection was conducted by a group of researchers, who received previous training. The following processes were developed: researcher's presentation; explanation about the research objective; interviewee's authorization; reading each sentence of the research instrument; offer time to answer each sentence (60 seconds) and the provision of impartial clarifications where necessary. The participants were questioned face to face.

Spearman's tests were used to evaluate the correlation between the rankings of each grouping. The rankings were established from the frequency and intensity of disturbances, as well as the degree of contribution of the factors. The groups were demarcated considering the demographic and behavioral characteristics of the musicians. The Spearman test assessed the level of association between the perceptions of different conglomerates. For example, are male and female musicians affected by the same disorders order?

The Mann-Whitney $U$ test was used to assess differences in medians between independent samples. The purpose was to verify if there were evidence to believe that the values of one group are 
distinguished from the other. Are musicians playing different instruments affected by the same intensity and frequency, considering a musculoskeletal disorder "X"?

Results

Most of the respondents was male (86.60\%), young people aged up to 33 years $(82.47 \%)$ and have up to 5 years of profession (71.14\%). Respondents, on average, reserved a time of dedication to the instrument of at most 3 hours per day (95.87\%) which reinforces the hypothesis of musical activity as an element underlying sustenance. Lüders and Gonçalves (2013) reported that it is common for musicians to perform professional activities in other areas. Idamoyibo (2017) also manifests similar thinking.

There was a supremacy of participants who reside and perform their musical activities in the city of Patos (58.76\%). Other neighboring territories were mentioned with less intensity, for example Teixeira and Água Branca. As for the category, there was a predominance of amateur musicians (86.60\%). Informality is a peculiar characteristic among Brazilian musicians (Lüders \& Gonçalves, 2013).

With regard to the instrument, those who like to play acoustic guitar stand out (80.41). In addition, most use right hand to play the instrument (89.69\%) and do not lengthen (62.89\%). This habit was also cited by Costa and Abrahão (2004).

\section{Assessment of risk factors and disorders}

Risk factors and musculoskeletal disorders associated with musical activity were assessed. For this, natural clusters were established, which were divided by demographic and behavioral criteria. These natural conglomerates comprise individuals who have similar aspects to each other. For example, women constituted one group while men formed another.

In all groups, the medians were used to capture the central value of the data set. The reason is because the scales used are ordinal. Thus, it is not possible to use techniques that work from the notion of Euclidean spaces. Medians were used to establish the positions of each disorder and risk factor, besides serving as input for application of the Spearman and Mann-Whitney $U$ tests. Disorders were assessed for intensity and frequency. Risk factors were measured based on the degree of contribution to the onset of diseases. 


\section{Groups based on demographic variables}

In the first moment, Spearman test was employed. The objective was to assess in which extent one group approached another. How much a conglomerate is dependent on another. Evaluations occurred for both musculoskeletal disorders and for risk factors. In the groups of age (Table 1), there was a moderate association (0.612) between the disorders perceived by young and older individuals. At the significance level of $6 \%$, it was found that the diseases that affect young musicians (up to 33 years) are very similar to those reported by older musicians. Problems in upper limbs and column were the most alarming diseases in the two clusters of age. Findings were in line with thesis of Kothe (2011).

In groups of gender, the result was divergent. There was no statistical evidence to ensure an association between disorders noted by men and women. Consequently, the disturbances that most affect the men are not the same reported by the female public. For example, men noticed the pains in the column as a problem with which they coexist more, whereas the women attributed to carpal tunnel syndrome. In parts, these findings have ratified the directions of Fragelli and Günther (2009), Teixeira et al. (2015). These studies indicated cervical and dorsal region as the most affected body region in musicians, independent of gender. 
Table 1 - Spearman test and medians (disorders) for groups of age, gender, time of study and profession

\begin{tabular}{|c|c|c|c|c|c|c|c|c|c|c|c|c|c|c|c|c|}
\hline \multirow{3}{*}{ Disorders } & \multicolumn{8}{|c|}{ Age (years) } & \multicolumn{8}{|c|}{ Gender } \\
\hline & \multicolumn{4}{|c|}{ Up to 33} & \multicolumn{4}{|c|}{ More than 33} & \multicolumn{4}{|c|}{ Male } & \multicolumn{4}{|c|}{ Female } \\
\hline & $M_{\text {freq }}$ & $\mathbf{M}_{\text {int }}$ & Weight & $\mathbf{P t}$ & $M_{\text {freq }}$ & $\mathbf{M}_{\text {int }}$ & Weight & $\mathbf{P t}$ & $M_{\text {freq }}$ & $\mathbf{M}_{\text {int }}$ & Weight & $\mathbf{P t}$ & $M_{\text {freq }}$ & $\mathbf{M}_{\text {int }}$ & Weight & $\mathbf{P t}$ \\
\hline Q1. Pains & 2 & 2 & 2 & 7.5 & 0 & 0 & 0 & 4 & 2 & 1 & 1.5 & 8 & 1 & 1 & 1 & 8 \\
\hline Q2. muscle problems in upper limbs & 3 & 3 & 3 & 9.5 & 1 & 1 & 1 & 9.5 & 3 & 3 & 3 & 9 & 1 & 1 & 1 & 8 \\
\hline Q3. inflammations in upper limbs & 0 & 0 & 0 & 3.5 & 0 & 0 & 0 & 4 & 0 & 0 & 0 & 3.5 & 0 & 0 & 0 & 3 \\
\hline Q4. column pains & 3 & 3 & 3 & 9.5 & 1 & 1 & 1 & 9.5 & 3.5 & 3 & 3.25 & 10 & 1 & 0 & 0.5 & 6 \\
\hline Q5. dizziness & 0 & 0 & 0 & 3.5 & 0 & 0 & 0 & 4 & 0 & 0 & 0 & 3.5 & 0 & 0 & 0 & 3 \\
\hline Q6. hearing problems & 0 & 0 & 0 & 3.5 & 0 & 0 & 0 & 4 & 0 & 0 & 0 & 3.5 & 0 & 0 & 0 & 3 \\
\hline Q7. vision problems & 0 & 0 & 0 & 3.5 & 1 & 0 & 0,5 & 8 & 0 & 0 & 0 & 3.5 & 0 & 0 & 0 & 3 \\
\hline Q8. Overuse syndrome & 0 & 0 & 0 & 3.5 & 0 & 0 & 0 & 4 & 0 & 0 & 0 & 3.5 & 0 & 0 & 0 & 3 \\
\hline Q9. Carpal tunnel syndrome & 0 & 0 & 0 & 3.5 & 0 & 0 & 0 & 4 & 0 & 0 & 0 & 3.5 & 1 & 2 & 1.5 & 10 \\
\hline Q10. Stress & 2 & 2 & 2 & 7.5 & 0 & 0 & 0 & 4 & 1 & 1 & 1 & 7 & 2 & 0 & 1 & 8 \\
\hline \multicolumn{9}{|c|}{ Spearman's rho $=0.6124^{*}$. Correlation is significant at 0.06} & \multicolumn{8}{|c|}{ Spearman's rho $=0.5466$. Correlation is not significant $(0.10)$} \\
\hline \multirow{3}{*}{ Disorders } & \multicolumn{8}{|c|}{ Study time per day (hours) } & \multicolumn{8}{|c|}{ Time of profession (years) } \\
\hline & \multicolumn{4}{|c|}{ Up to 3} & \multicolumn{4}{|c|}{ More than 3} & \multicolumn{4}{|c|}{ Up to 5} & \multicolumn{4}{|c|}{ More than 5} \\
\hline & $M_{\text {freq }}$ & Mint & Weight & $\mathbf{P t}$ & $M_{\text {freq }}$ & $\mathbf{M}_{\text {int }}$ & Weight & $\mathbf{P t}$ & $M_{\text {freq }}$ & Mint & Weight & $\mathbf{P t}$ & $M_{\text {freq }}$ & $\mathbf{M}_{\text {int }}$ & Weight & $\mathbf{P t}$ \\
\hline Q1. Pains & 2 & 1 & 1.5 & 8 & 2 & 1.5 & 1.75 & 5 & 2 & 1 & 1.5 & 8.5 & 2.5 & 2 & 2.25 & 7 \\
\hline Q2. muscle problems in upper limbs & 2 & 3 & 2.5 & 10 & 6 & 6 & 6 & 10 & 1 & 2 & 1.5 & 8.5 & 3.5 & 3 & 3.25 & 8 \\
\hline Q3. inflammations in upper limbs & 0 & 0 & 0 & 3.5 & 0 & 0 & 0 & 1.5 & 0 & 0 & 0 & 3 & 0 & 0.5 & 0.25 & 5 \\
\hline Q4. column pains & 2 & 2 & 2 & 9 & 6 & 5.5 & 5.75 & 9 & 2 & 2 & 2 & 10 & 4.5 & 3 & 3.75 & 9.5 \\
\hline Q5. dizziness & 0 & 0 & 0 & 3.5 & 0 & 0 & 0 & 1.5 & 0 & 0 & 0 & 3 & 0 & 0 & 0 & 2.5 \\
\hline Q6. hearing problems & 0 & 0 & 0 & 3.5 & 1 & 1 & 1 & 4 & 0 & 0 & 0 & 3 & 0 & 0 & 0 & 2.5 \\
\hline Q7. vision problems & 0 & 0 & 0 & 3.5 & 3.5 & 2.5 & 3 & 7 & 0 & 0 & 0 & 3 & 1 & 0 & 0.5 & 6 \\
\hline Q8. Overuse syndrome & 0 & 0 & 0 & 3.5 & 3.5 & 1.5 & 2.5 & 6 & 1 & 1 & 1 & 7 & 0 & 0 & 0 & 2.5 \\
\hline Q9. Carpal tunnel syndrome & 0 & 0 & 0 & 3.5 & 0.5 & 0 & 0.25 & 3 & 0 & 0 & 0 & 3 & 0 & 0 & 0 & 2.5 \\
\hline Q10. stress & 1 & 1 & 1 & 7 & 4.5 & 3 & 3.75 & 8 & 1 & 0 & 0.5 & 6 & 4.5 & 3 & 3.75 & 9.5 \\
\hline
\end{tabular}

Spearman's rho $=0.7534^{*}$. Correlation is significant at 0.01

Note. $\mathrm{M}_{\text {freq }}$ : median of frequency parameter. $\mathrm{M}_{\text {int }}$ : median of intensity parameter. Weight: value considered to rank the disorders (median between frequency and intensity scores). Pt: are the positions of each disorder, considering the spearman test procedure. $\left(^{*}\right) 2$-tailed. 
Table 2 - Spearman test and medians (risk factors) for groups of age, gender, time of study and profession

\begin{tabular}{|c|c|c|c|c|c|c|c|c|}
\hline \multirow{3}{*}{ Risk factors } & \multicolumn{4}{|c|}{ Age (years) } & \multicolumn{4}{|c|}{ Gender } \\
\hline & \multicolumn{2}{|c|}{ Up to 33} & \multicolumn{2}{|c|}{ More than 33} & \multicolumn{2}{|c|}{ Male } & \multicolumn{2}{|c|}{ Female } \\
\hline & $\mathbf{M}$ & $\mathbf{P t}$ & $\mathbf{M}$ & $\mathbf{P t}$ & $\mathbf{M}$ & $\mathbf{P t}$ & $\mathbf{M}$ & $\mathbf{P t}$ \\
\hline F1. study time (includes practice and rehearsals) & 6 & 5.5 & 9 & 8.5 & 6 & 5.5 & 6 & 3.5 \\
\hline F2. repetitive movements & 6 & 5.5 & 9 & 8.5 & 6 & 5.5 & 7 & 9.5 \\
\hline F3. Stress and pressure & 6 & 5.5 & 8 & 5 & 6 & 5.5 & 7 & 9.5 \\
\hline F4. inadequate postures/maintenance of static posture & 7.5 & 13 & 10 & 12 & 8 & 13 & 7 & 9.5 \\
\hline F5. furniture and accessories & 6.5 & 10 & 10 & 12 & 7 & 11.5 & 7 & 9.5 \\
\hline F6. environmental conditions & 6 & 5.5 & 7 & 2.5 & 6 & 5.5 & 6 & 3.5 \\
\hline F7. repertory level & 5.5 & 1 & 10 & 12 & 6 & 5.5 & 5 & 1 \\
\hline F8. Characteristics of the instrument. & 6 & 5.5 & 9 & 8.5 & 6 & 5.5 & 7 & 9.5 \\
\hline F9. Strength exerted when playing. & 6 & 5.5 & 8 & 5 & 6 & 5.5 & 6 & 3.5 \\
\hline F10. Instrument weight & 7 & 11.5 & 6 & 1 & 6 & 5.5 & 7 & 9.5 \\
\hline F11. Intensity of training & 6 & 5.5 & 7 & 2.5 & 6 & 5.5 & 7 & 9.5 \\
\hline F12. Quality of sheet music & 6 & 5.5 & 8 & 5 & 6 & 5.5 & 6 & 3.5 \\
\hline F13. Insufficient pauses for rest. & 7 & 11.5 & 9 & 8.5 & 7 & 11.5 & 7 & 9.5 \\
\hline \multicolumn{5}{|l|}{ Spearman's rho $=0.0677$. Correlation is not significant $(0.83)$. } & \multicolumn{4}{|c|}{ Spearman's rho $=0.4217$. Correlation is not significant $(0.15)$} \\
\hline \multirow{3}{*}{ Risk factors } & \multicolumn{4}{|c|}{ Study time per day (hours) } & \multicolumn{4}{|c|}{ Time of profession (years) } \\
\hline & \multicolumn{2}{|c|}{ Up to 3} & \multicolumn{2}{|c|}{ More than 3} & \multicolumn{2}{|c|}{ Up to 5} & \multicolumn{2}{|c|}{ More than 5} \\
\hline & $\mathbf{M}$ & $\mathbf{P t}$ & $\mathbf{M}$ & $\mathbf{P t}$ & $\mathbf{M}$ & $\mathbf{P t}$ & $\mathbf{M}$ & $\mathbf{P t}$ \\
\hline F1. study time (includes practice and rehearsals) & 6 & 5 & 6.5 & 9.5 & 6 & 5 & 6 & 6 \\
\hline F2. repetitive movements & 6 & 5 & 5.5 & 2.5 & 7 & 11 & 6 & 6 \\
\hline F3. Stress and pressure & 6 & 5 & 6 & 5.5 & 6 & 5 & 5 & 1 \\
\hline F4. inadequate postures/maintenance of static posture & 8 & 13 & 6.5 & 9.5 & 8 & 13 & 7 & 11.5 \\
\hline F5. furniture and accessories & 7 & 11 & 5.5 & 2.5 & 6 & 5 & 7 & 11.5 \\
\hline F6. environmental conditions & 6 & 5 & 7 & 12 & 6 & 5 & 6 & 6 \\
\hline F7. repertory level & 6 & 5 & 6.5 & 9.5 & 6 & 5 & 6 & 6 \\
\hline F8. Characteristics of the instrument. & 6 & 5 & 6.5 & 9.5 & 6 & 5 & 6 & 6 \\
\hline F9. Strength exerted when playing. & 6 & 5 & 5 & 1 & 6 & 5 & 6.5 & 10 \\
\hline F10. Instrument weight & 7 & 11 & 6 & 5.5 & 7 & 11 & 6 & 6 \\
\hline F11. Intensity of training & 6 & 5 & 6 & 5.5 & 6 & 5 & 6 & 6 \\
\hline F12. Quality of sheet music & 6 & 5 & 8 & 13 & 6 & 5 & 5.5 & 2 \\
\hline F13. Insufficient pauses for rest. & 7 & 11 & 6 & 5.5 & 7 & 11 & 7.5 & 13 \\
\hline Spearman's rho $=-0.1743$. Correlation is not significant $(0.57)$. & & & & & Spearma & 0.442 & lation & nt $(0.13)$. \\
\hline
\end{tabular}


As for the risk factors, similarities were not observed between groups of gender and age, because correlation coefficients were statistically insignificant (Table 2). For men, elements that most contribute to the development of musculoskeletal disorders are not similar to those enumerated by women. Men cited inadequate postures as main risk factor, while the female public added this to other aspects: repetitive movements, stress, furniture, instrument characteristics, intensity of training and lack of pauses.

There were divergences between perceptions of young and older musicians. The two conglomerates cited inadequate positions as main element. However, instrumentalists over the age of 33 also put other elements on the same hierarchical level of contribution: inappropriate furniture and repertory level.

Similar reports were found in the literature. Teixeira et al. (2015), Andrade and Fonseca (2000) had reported maintaining a posture for long periods as one of the factors that most develop musculoskeletal injuries in musicians. Along the same lines, Costa and Abrahão (2004) indicated that the presence of reported complaints among violists came from maintaining rigid posture together with time they remain static.

\section{Groups defined in behavioral variables}

Study and profession time was not a differentiating factor. Generally, musicians are affected by the same musculoskeletal problems, independent of time they dedicate to rehearsals or time they are in the profession. There were moderate similarities in intensity and frequency with which disturbances appear in instrumentalists who play more than 3 hours per day and those less active. Spearman coefficient reached the order of 0.75 (significance of 0.01). This confronted the notes of Andrade and Fonseca (2000). For these authors, as musicians increase the training loads the intensity with which disturbances arise increases.

Already in groups by time of profession, the evidences were analogous. There was a moderate similarity (0.67 at the level of 0.03$)$ between disturbances perceived by the musicians who rehearse up to 3 hours and by others who dedicate superior time. For those who have been in the profession for more than 5 years, column pains and stress were more frequent symptoms. For the less experienced (under 5 years of occupation), only lumbar lesions occupied this position.

In risk factors, the Spearman coefficients were statistically insignificant for clusters of study and profession time. Therefore, there is no evidence of approximation between perceptions of distinct groups. Musicians who play the most (above 3 hours a day) assign an order of causative agents quite different of the one mentioned by less active instrumentalists. For example, the main risk factors for individuals who played more than 3 hours were: instrument characteristics, repertoire level, rehearsal 
time and inappropriate postures. On the other hand, only the last risk factor was enumerated by the less active category.

As for the time of profession, the situation remained. More experienced musicians - with more than 5 years - reported that major risk factors were different elements from those discussed by the inexperienced. While inconstant pauses stood out for the most experienced class, inadequate postures were pointed as the main risk factor in the view of musicians with less than 5 years of profession.

The levels of association of disorders between groups defined by category, type of instrument and stretching routine were significant and with moderate to strong intensities (Table 3). Spearman coefficients ranged from 0.76 (category) to 0.89 (instrument).

It has been found that professional and amateur musicians suffer from the same musculoskeletal problems. Both categories cited complaints in column and upper limbs as most common symptoms. Another outstanding issue was that professional instrumentalists suffered more intense actions of stress. This scenario was observed by Baadjou et al. (2016).

On the other hand, type of instrument that musicians play was not primordial to differentiate disturbances that they feel. The subjects that play acoustic guitar coexist with musculoskeletal pain very similar to those of another class of musician (electric guitar). Column and upper limbs were the body regions most affected. Equivalent panorama was indicated by groups performing (or not) stretching exercises. This leads to the hypothesis that, regardless of do (or not) stretching, instrumentalists are predisposed to develop similar pathologies in intensity and frequency. 
Table 3 - Spearman test and medians (disorders) for groups of category, dominant hand, instrument and stretching

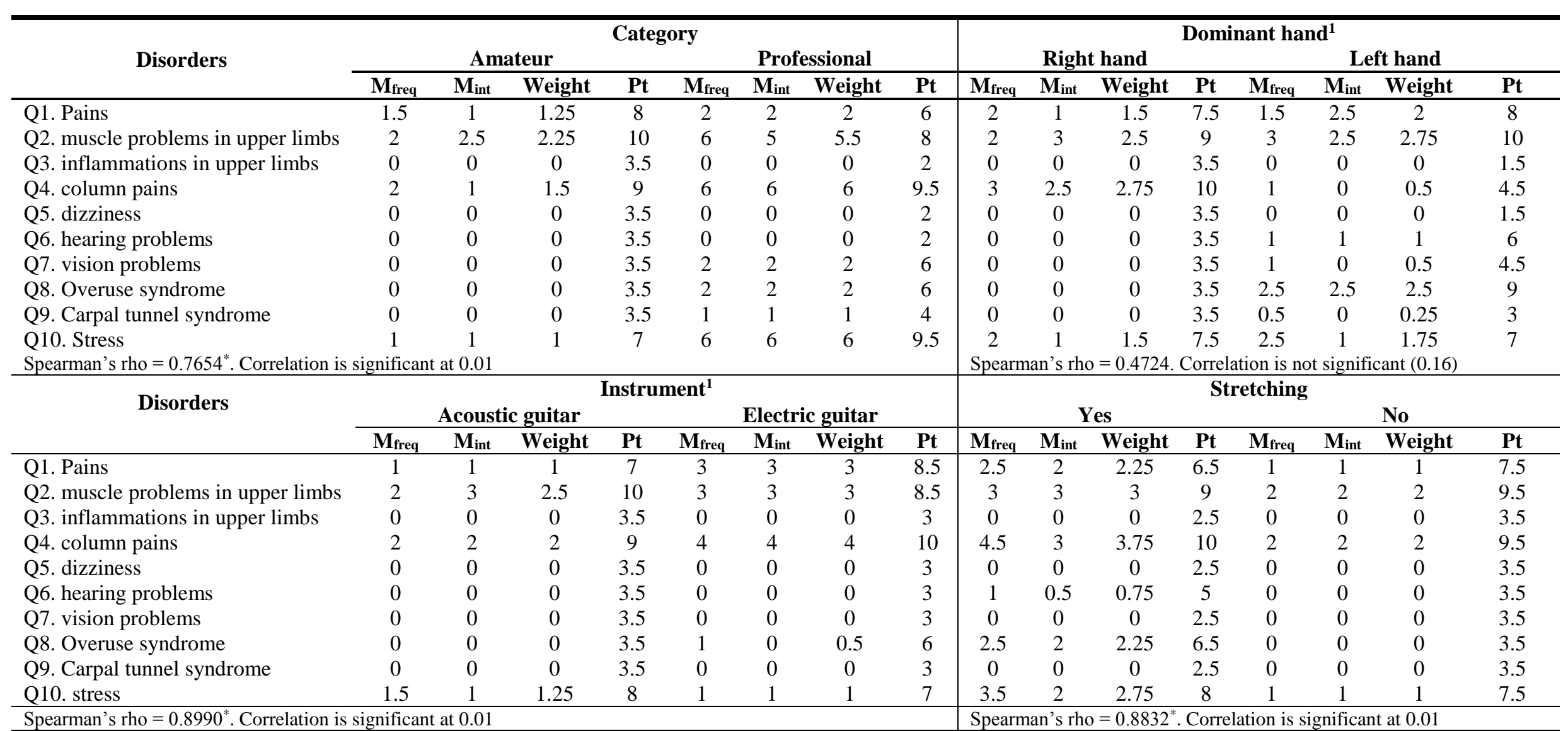

Spearman's rho $=0.8990^{*}$. Correlation is significant at 0.01

Note. $\mathrm{M}_{\text {freq }}$ : median of frequency parameter. $\mathrm{M}_{\mathrm{int}}$ : median of intensity parameter. Weight: value considered to rank the disorders (median between frequency and intensity scores). Pt: are the positions of each disorder, considering the spearman test procedure. (*) 2-tailed. (1) Ambidextrous and those who play bass were excluded from analysis because of the low number of respondents (four and six, respectively). 
Table 4 - Spearman test and medians (risk factors) for groups of category, dominant hand, instrument and stretching

\begin{tabular}{|c|c|c|c|c|c|c|c|c|}
\hline \multirow{3}{*}{ Risk factors } & \multicolumn{4}{|c|}{ Category } & \multicolumn{4}{|c|}{ Dominant hand } \\
\hline & \multicolumn{2}{|c|}{ Amateur } & \multicolumn{2}{|c|}{ Professional } & \multicolumn{2}{|c|}{ Right hand } & \multicolumn{2}{|c|}{ Left hand } \\
\hline & $\mathbf{M}$ & $\mathbf{P t}$ & $\mathbf{M}$ & $\mathbf{P t}$ & $\mathbf{M}$ & $\mathbf{P t}$ & $\mathbf{M}$ & $\mathbf{P t}$ \\
\hline F1. study time (includes practice and rehearsals) & 6 & 5 & 7 & 11.5 & 6 & 5.5 & 5.5 & 2 \\
\hline F2. repetitive movements & 6 & 5 & 8 & 13 & 6 & 5.5 & 6 & 4.5 \\
\hline F3. Stress and pressure & 6 & 5 & 6 & 7 & 6 & 5.5 & 5.5 & 2 \\
\hline F4. inadequate postures/maintenance of static posture & 8 & 12.5 & 6 & 7 & 8 & 13 & 8 & 12 \\
\hline F5. furniture and accessories & 7 & 10.5 & 6 & 7 & 7 & 11.5 & 7.5 & 10.5 \\
\hline F6. environmental conditions & 6 & 5 & 7 & 11.5 & 6 & 5.5 & 7.5 & 10.5 \\
\hline F7. repertory level & 6 & 5 & 5 & 2.5 & 6 & 5.5 & 5.5 & 2 \\
\hline F8. Characteristics of the instrument. & 6 & 5 & 6 & 7 & 6 & 5.5 & 7 & 7.5 \\
\hline F9. Strength exerted when playing. & 6 & 5 & 6 & 7 & 6 & 5.5 & 7 & 7.5 \\
\hline F10. Instrument weight & 7 & 10.5 & 5 & 2.5 & 6 & 5.5 & 7 & 7.5 \\
\hline F11. Intensity of training & 6 & 5 & 6 & 7 & 6 & 5.5 & 7 & 7.5 \\
\hline F12. Quality of sheet music & 6 & 5 & 3 & 1 & 6 & 5.5 & 6 & 4.5 \\
\hline F13. Insufficient pauses for rest. & 8 & 12.5 & 6 & 7 & 7 & 11.5 & 9 & 13 \\
\hline \multicolumn{5}{|l|}{ Spearman's rho $=-0.1819$. Correlation is not significant $(0.55)$} & \multicolumn{4}{|c|}{ Spearman's rho $=0.7200^{*}$. Correlation is significant at 0.01} \\
\hline \multirow{3}{*}{ Risk factors } & \multicolumn{4}{|c|}{ Instrument } & \multicolumn{4}{|c|}{ Stretching } \\
\hline & \multicolumn{2}{|c|}{ Acoustic guitar } & \multicolumn{2}{|c|}{ Electric guitar } & \multicolumn{2}{|c|}{ Yes } & \multicolumn{2}{|c|}{ No } \\
\hline & $\mathbf{M}$ & $\mathbf{P t}$ & $\mathbf{M}$ & $\mathbf{P t}$ & $\mathbf{M}$ & $\mathbf{P t}$ & $\mathbf{M}$ & $\mathbf{P t}$ \\
\hline F1. study time (includes practice and rehearsals) & 6 & 5 & 6 & 5 & 6 & 7 & 6 & 4 \\
\hline F2. repetitive movements & 7 & 11 & 6 & 5 & 6 & 7 & 7 & 10 \\
\hline F3. Stress and pressure & 6 & 5 & 6 & 5 & 5.5 & 2 & 6 & 4 \\
\hline F4. inadequate postures/maintenance of static posture & 8 & 13 & 8 & 13 & 7 & 13 & 9 & 13 \\
\hline F5. furniture and accessories & 7 & 11 & 7 & 10.5 & 6 & 7 & 7 & 10 \\
\hline F6. environmental conditions & 6 & 5 & 7 & 10.5 & 6 & 7 & 6 & 4 \\
\hline F7. repertory level & 6 & 5 & 6 & 5 & 5 & 1 & 6 & 4 \\
\hline F8. Characteristics of the instrument. & 6 & 5 & 5 & 1 & 6 & 7 & 6 & 4 \\
\hline F9. Strength exerted when playing. & 6 & 5 & 6 & 5 & 6 & 7 & 7 & 10 \\
\hline F10. Instrument weight & 6 & 5 & 7 & 10.5 & 6 & 7 & 7 & 10 \\
\hline F11. Intensity of training & 6 & 5 & 6 & 5 & 6 & 7 & 6 & 4 \\
\hline F12. Quality of sheet music & 6 & 5 & 6 & 5 & 6 & 7 & 6 & 4 \\
\hline F13. Insufficient pauses for rest. & 7 & 11 & 7 & 10.5 & 6.5 & 12 & 7 & 10 \\
\hline Spearman's rho $=0.5833^{*}$. Correlation is significant at 0.04 & & & & & Spearman & 0.6338 & latiol & 0.02 \\
\hline
\end{tabular}

Note. M: median of values attributed to the degree of contribution of each risk factor. Pt: are the positions of each risk factor, considering the spearman test procedure. 
As for the dominant hand, Spearman's coefficient did not support correlation. The hand with which it plays the instrument has generated divergences between perceptions of pathologies. While pains in the column integrated the main disturbance for right-handed musicians, muscular complaints in the upper limbs occupied this position in the view of left-handed people.

Regarding risk factors (Table 4), the different categories presented divergences between them. Factors cited by amateur musicians do not equate to those that were listed by professionals. Professionals asserted repetitive movements as the main cause for the disorders. Different optic presented the amateurs who put inappropriate postures as the great villain.

Considering clusters formed by dominant hand, instrument and stretching, similarities were found. Spearman's coefficients ranged from 0.58 to 0.72 . Risk factors indicated by right-handed and left-handed musicians do not diverge.

\section{Exploring differences from Mann-Whitney $U$ test}

Mann-Whitney $U$ test was used to compare values of central tendency between two independent samples. A total of 184 valuations, pair wise, were performed (Table 5). Significance level of 0.05 was adopted. If greater separation of data were evidenced, the null hypothesis of equality between the medians was rejected. Then, two groups presented different behaviors for a given disorder or risk factor.

When analyzing each disorder and risk factor, considering group to group, only twenty observations were significant (marked in gray). There were no differences only between gender and dominant hand groups. In other clusters, differences were found in at least one item. The category and age conglomerates were the ones that had the most discrepancies. Seven and six evidences emerged in these clusters, respectively. Differences were stronger in the axis of the risk factors for the age conglomerates 
Table 5 - Levels of significance of Mann-Whitney $U$ test

\begin{tabular}{|c|c|c|c|c|c|c|c|c|}
\hline \multirow{3}{*}{ Disorders } & \multicolumn{8}{|c|}{ Groups } \\
\hline & Age & Gender & Study time & Time of profession & Category & Dominant hand & Instrument & Stretching \\
\hline & \multicolumn{8}{|c|}{ levels of significance } \\
\hline Q1. Pains & $0.003^{*}$ & 0.850 & 0.567 & 0.295 & 0.337 & 0.976 & 0.314 & $0.029^{*}$ \\
\hline Q2. muscle problems in upper limbs & 0.462 & 0.283 & $0.022^{*}$ & $0.001^{*}$ & $0.001 *$ & 0.921 & 0.123 & 0.814 \\
\hline Q3. inflammations in upper limbs & 0.680 & 0.730 & 0.434 & 0.181 & 0.872 & 0.619 & 0.893 & 0.707 \\
\hline Q4. column pains & 0.323 & 0.108 & 0.210 & 0.375 & $0.019^{*}$ & 0.204 & 0.387 & 0.302 \\
\hline Q5. dizziness & 0.935 & 0.674 & 0.759 & 0.397 & $0.042^{*}$ & 0.346 & 0.409 & 0.676 \\
\hline Q6. hearing problems & 0.814 & 0.995 & 0.694 & 0.581 & 0.373 & 0.798 & $0.030^{*}$ & 0.080 \\
\hline Q7. vision problems & 0.170 & 0.845 & 0.184 & 0.087 & $0.020^{*}$ & 0.890 & 0.260 & 0.239 \\
\hline Q8. Overuse syndrome & 0.584 & 0.818 & 0.488 & 0.532 & 0.545 & 0.370 & 0.060 & 0.606 \\
\hline Q9. Carpal tunnel syndrome & 0.327 & 0.179 & 0.882 & 0.462 & 0.114 & 0.793 & 0.781 & 0.676 \\
\hline Q10. Stress & 0.118 & 0.892 & 0.284 & $0.028^{*}$ & $0.003^{*}$ & 0.563 & 0.171 & 0.259 \\
\hline \multicolumn{9}{|l|}{ Risk factors } \\
\hline F1. study time (includes practice and rehearsals) & $0.012^{*}$ & 0.619 & 0.393 & 0.364 & 0.194 & 0.333 & 0.616 & 0.283 \\
\hline F2. repetitive movements & $0.005^{*}$ & 0.386 & 0.511 & 0.387 & 0.315 & 0.303 & 0.390 & 0.294 \\
\hline F3. Stress and pressure & 0.439 & 0.565 & 0.868 & 0.069 & 0.427 & 0.994 & 0.187 & 0.454 \\
\hline F4. inadequate postures/maintenance of static posture & 0.235 & 0.494 & 0.557 & 0.674 & 0.195 & 0.790 & $0.042^{*}$ & 0.541 \\
\hline F5. furniture and accessories & $0.021^{*}$ & 0.809 & 0.854 & 0.806 & 0.851 & 0.596 & 0.169 & 0.243 \\
\hline F6. environmental conditions & 0.190 & 0.864 & 0.534 & 0.791 & 0.522 & 0.369 & 0.958 & 0.235 \\
\hline F7. repertory level & $0.002^{*}$ & 0.806 & 0.707 & 0.694 & 0.345 & 0.645 & $0.012^{*}$ & 0.581 \\
\hline F8. Characteristics of the instrument. & $0.013^{*}$ & 0.267 & 0.630 & 0.664 & 0.590 & 0.139 & 0.871 & 0.566 \\
\hline F9. Strength exerted when playing. & 0.100 & 0.773 & 0.178 & 0.971 & 0.121 & 0.618 & 0.119 & 0.333 \\
\hline F10. Instrument weight & 0.992 & 0.224 & 0.488 & 0.218 & 0.063 & 0.958 & 0.074 & 0.691 \\
\hline F11. Intensity of training & 0.401 & 0.463 & 0.882 & 0.080 & 0.268 & 0.745 & 0.190 & 0.345 \\
\hline F12. Quality of sheet music & 0.376 & 0.485 & 0.369 & 0.231 & $0.034^{*}$ & 0.789 & 0.485 & 0.977 \\
\hline F13. Insufficient pauses for rest. & 0.178 & 0.885 & 0.733 & 0.840 & $0.048^{*}$ & 0.213 & 0.176 & 0.543 \\
\hline
\end{tabular}


In an approach for disturbances or risk factor, the greatest number of differences were recorded in muscle problems in upper limbs (Q2, 3 cases), Stress (Q10, 2 cases), pains (Q1, 2 cases) e repertory level (F7, 2 cases). No divergence was identified in the items: inflammations in upper limbs (Q3), overuse syndrome (Q8), carpal tunnel syndrome (Q9), stress and pressure (F3), environmental conditions (F6), strength exerted when playing (F9), instrument weight (F10), intensity of training (F11).

\section{Discussion}

Among eight criteria evaluated, similarities between intensity and frequency of musculoskeletal disorders were sustained in six types of groups. Different groups of age, study time, time of profession, category, type of instrument and stretching complained of the same symptoms. Spearman coefficients, with oscillations between 0.61 (age groups) and 0.89 (groups of instrument), corroborated these directions. Male and female musicians, for example, suffer from the same ills. There were also indications that musicians with more time of profession coexist with the same disturbances, in order of intensity and frequency, compared to musicians whose career is more recent. Therefore, evidence were also supported by results of the Mann-Whitney $U$ test. For the same clusters, the number of divergences (by disturbance or risk factor) was reduced. In conglomerates of age, study time, instrument and stretching, there was only a single distinction between the medians of the two samples. In clusters of time of profession and category, this quantitative jumps to two $(\mathrm{Q} 2, \mathrm{Q} 10)$ and five $(\mathrm{Q} 2, \mathrm{Q} 4, \mathrm{Q} 5, \mathrm{Q} 7, \mathrm{Q} 10)$ respectively.

These findings are contrary the directions of certain empirical studies. Papandreou and Vervainioti (2010) found significant correlations between musculoskeletal disorders and the following variables: age and musical practice time. For theorists, pain in the dorsal region was associated with older people $(r=0.48)$. Likewise, they cited a relation between prevalence of neuralgias in the arms with time of profession ( $r=0.45)$. In the same line, Amorim et al. (2008) concluded that greater professional experience in the field of music provides a more compromised audiometric threshold. Watson (2006) also added that intensive training triggers focal dystonias in the hands. In turn, Kok et al. (2016) cited a lower incidence of musculoskeletal complaints in metal instrumentalists.

In groups of gender and dominant hand, relationships between groups were not supported. Nothing can be said about disturbances when confronted with female and male musicians, as well as those who play with the right or left hand. Spearman's coefficients were statistically insignificant. Cruder et al. (2017), for example, also found no evidence to show the relationship between gender and pain. Moreover, the present study did not identify differences between medians of different samples - either for groups of gender or dominant hand. In these cases, this points to non-robust results. There is a need for other empirical papers that explore deeply relations of gender, dominant hand and disorders. 
As for the risk factors, there was no evidence for similarities between clusters. The conglomerates of age, gender, study time, time of profession and category presented insignificant scores for Spearman correlation. It is not possible to say that there were similarities or differences between the groups. There is independence between them. Complementarily, for the most part, Mann-Whitney $U$ tests did not show any differences. This indicates a nebulous zone that prevents concrete conclusions.

In addition, groupings by type of instrument and stretching presented consistent results. Spearman coefficients were 0.89 (instrument) and 0.88 (stretching). This indicated that musculoskeletal disorders perceived by musicians who play acoustic guitar were similar to those reported by musicians who play electric guitar. Other epidemiological studies have reported similar findings. Kaufman-Cohen and Ratzon (2011), for example, have mentioned that string musicians suffer from more intense musculoskeletal disorders than wind instruments.

On the other hand, the musicians who stretch themselves suffer the same symptoms in relation to those who do not have this habit, including similar frequencies and intensities. This finding reinforced the directions of Lonsdale and Laakso (2014). For the authors, the isolated application of stretching techniques does not constitute an optimal solution for prevention of musculoskeletal injuries in musicians.

\section{Conclusions}

The aim of the present study was to investigate in which extent the musculoskeletal disorders and risk factors oscillate between different groups. Groups were originated from eight demographic and behavioral variables: gender, age, study time, time of profession, category, dominant hand, type of instrument and stretching. In six classes of groupings, similarities (moderate or strong) were observed in intensity and frequency with which musculoskeletal problems manifested themselves. This did not occur in clusters of gender and dominant hand. It is possible to say, for example, that younger musicians suffer from the same symptoms compared to older ones. Therefore, different therapeutic techniques do not need to be applied to musicians of different ages.

A significant degree of similarity between the risk factors occurred only between groups of type of instrument, dominant hand and stretching. In general, there were no evidence to indicate that predictors of musculoskeletal disorders were similar or divergent among conglomerates. It was not possible to know if what caused musculoskeletal complaints in amateur musicians was also responsible for the symptoms in professional musicians. In addition, the bodily regions most affected were upper 
limbs and column. This confirmed the findings of Papandreou and Vervainioti (2010). In turn, inadequate posture represented the element that most cooperated for the arise of musculoskeletal disjunctions.

Limitations circumscribed the present study, such as: non-probabilistic sample, reduced number of participating cities, cross-sectional drawing and exclusion of musicians engaged in other instruments. Thus, results of this research only reflected the context and time space studied and generalizations should not be conceived.

\section{References}

Amorim, R. B., Lopes, A. C., Santos, K. T. P., Melo, A. D. P., \& Lauris, J. R. P. (2008). Auditory Alterations for Occupational Exposition in Musicians. International Archives of Otorhinolaryngology, 12: 377383.

Andersen J. H., Kaergaard A., \& Mikkelsen S. (2003). Risk factors in the onset of neck/shoulder pain in a prospective study of workers in industrial and service companies. Occupational and Environmental Medicine, 60: 649-654.

Andrade, E. Q., \& Fonseca, J. G. M. (2000). Artista-atleta: reflexões sobre a utilização do corpo na performance dos instrumentos de cordas. Performance Musical, 2: 118-128.

Andrade, A. I. A., Russo, I. C. P., Lima, M. L. L. T., \& Oliveira, L. C. S. (2002). Avaliação auditiva em músicos de frevo e maracatu. Revista Brasileira De Otorrinolaringologia, 68.

Baadjou, V. A. E., Roussel, N. A., Verbunt, J. A. M. C. F., Smeets, R. J. E. M., \& Bie, R. A. (2016). Systematic review: risk factors for musculoskeletal disorders in musicians. Occupational Medicine, 66: 614622.

Blanco-Piñeiro, P., Díaz-Pereira, M. P., \& Martínez, A. (2017). Musicians, postural quality and musculoskeletal health: A literature's review. Journal of Bodywork and Movement Therapies, 21: 157-172.

Brandfonbrener, A. G. (2003). Musculoskeletal problems of instrumental musicians. Hand Clinics, 19: 231-239.

Brown, J. D. (2015). Questions and answers about language testing statistics: Characteristics of sound quantitative research. Shiken, 19: 24-28.

Carneiro, P., Braga, A. C., \& Barroso, M. (2017). Work-related musculoskeletal disorders in home care nurses: study of the main risk factors. International Journal of Industrial Ergonomics, 61: 22-28.

Cheng, H. K., Wong, M., Yu, Y., \& Ju, Y. (2016). Work-related musculoskeletal disorders and ergonomic risk factors in special education teachers and teacher's aides. BMC Public Health, 16.

Costa, C. P., \& Abrahão, J. I. (2004). Quando o tocar dói: um olhar ergonômico sobre o fazer musical. Per Musi, 10: 60-79.

Costa, C. P. (2005). Contribuições da ergonomia à saúde do Músico: considerações sobre a dimensão física do fazer musical. Música Hodie, 5.

Cruder, C., Falla, D., Mangili, F., Azzimonti, L., Araújo, L. S., Williamon, A., \& Barbero M. (2017). Profiling the Location and Extent of Musicians' Pain Using Digital Pain Drawings. Pain Practice.

Engquist, K., Orbaek, P., \& Jakobsson, K. (2004). Musculoskeletal pain and impact on performance in orchestra musicians and actors. Medical Problems of Performing Artists, 19.

Frank, A., Von Mühlen, C. A. (2007). Queixas musculoesqueléticas em músicos: prevalência e fatores de risco. Revista Brasileira de Reumatologia, 47: 188-196.

Fragelli, T. B. O., Günther, I. A. (2009). Relação entre dor e antecedentes de adoecimento físico ocupacional: um estudo entre músicos instrumentistas. Performance Musical, 19: 18-23.

Harkness E. F., Macfarlane G. J., \& Nahit E. S. (2003). Risk factors for new-onset low back pain amongst cohorts of newly employed workers. Rheumatology, 42: 959-968. 
Heinan, M. (2008). A review of the unique injuries sustained by musicians. Journal of the American Academy of Physician Assistants, 21: 45-52.

Instituto Brasileiro de Geografia e Estatística. Estatísticas. Available online: www.ibge.gov.br (accessed on October 2th, 2017).

Idamoyibo, A. A. (2017). The impact of dúndùn drummers on the development of traditional music in south west Nigeria. African Musicology Online, 7: 1-19.

Kaergaard A., \& Andersen J. H. (2000). Musculoskeletal disorders of the neck and shoulders in female sewing machine operators: prevalence, incidence, and prognosis. Occupational and Environmental Medicine, 57: 528-534.

Kaufman-Cohen, Y., \& Ratzon, N. Z. (2011). Correlation between risk factors and musculoskeletal disorders among classical musicians. Occupational Medicine, 61: 90-95.

Kok, L. M., Huisstede, B. M. A., Voorn, V. M. A., Schoones, J. W., \& Nelissen, R. G. (2016). The occurrence of musculoskeletal complaints among professional musicians: a systematic review. International Archives of Occupational and Environmental Health, 89: 373-396.

Kothe, F. et al. (2011). A prática musical na inicialização e as queixas musculoesqueléticas. Revista Música Hodie, 11: 183-199.

Lee, H. S., Park, H. Y., Yoon, J. O., Kim, J. S., Chun, J. M., Aminata, I. W., Cho, W. J., \& Jeon I. H. (2013). Musicians' medicine: musculoskeletal problems in string players. Clinics Orthopedic Surgery, 5: 155160.

Leaver R., Harris E. C., \& Palmer K. T. (2011). Musculoskeletal pain in elite professional musicians from British symphony orchestras. Occupational Medicine, 61: 549-555

Lonsdale, K. A., \& Laakso, L. (2014). Preventing Flute Playing-related Musculoskeletal Disorders: Applying Ergonomic Principles in Individual and Ensemble Settings. Malaysian Music Journal, 3: 6781.

Lüders, D., \& Gonçalves, C. G. (2013). Trabalho e saúde na profissão de músico: reflexões sobre um artista trabalhador. Tuiuti: Ciência e Cultura, 47: 123-137.

Mendes, M. H., \& Morata, T. C. (2007). Exposição profissional à música: uma revisão. Revista da Sociedade Brasileira de Fonoaudiologia, 12: 63-69.

Middlestadt, S. E., \& Fishbein, M. (1989). The prevalence of severe musculoskeletal problems among male and female symphony orchestra string players. Medical Problems Of Performing Artists, 4: 4148.

Moura, R. C. R., Fontes, S. V., \& Fukujima, M. M. (2000). Doenças ocupacionais em músicos: uma abordagem fisioterapêutica. Revista Neurociências, 8: 103-107.

Paarup H. M., Baelum J., Holm J. W., Manniche C., \& Wedderkopp N. (2011). Prevalence and consequences of musculoskeletal symptoms in symphony orchestra musicians vary by gender: a cross-sectional study. BMC Musculoskelet Disord.

Papandreou, M., \& Vervainioti, A. (2010). Work-related Musculoskeletal Disorders Among Percussionists in Greece: A Pilot Study. Medical Problems of Performing Artists, 1: 116-119.

Pederiva, P. L. (2004). A relação músico-corpo-instrumento: procedimentos pedagógicos. Revista da ABEM 11: 91-98.

Pereira Filho, E., \& Silva, J. R. (2017). Development of a scale to evaluate musculoskeletal disorders and risk factors in string musicians. Revista Brasileira de Saúde e Segurança no Trabalho, 1: 7-12.

Sousa, C. M., Machado, J. P., Greten, H. J., \& Coimbra, D. (2016). Occupational diseases of professional orchestra musicians from northern portugal: a descriptive study. Medical Problems of Performing Artists, 31.

Stanhope J., \& Milanese S. (2015). The prevalence and incidence of musculoskeletal symptoms experienced by flautists. Occupational Medicine, 1: 1-8.

Teixeira, C. S., Andrade, R. D., Kothe, F., \& Felden, E. (2015). Prática instrumental e desconforto corporal: um estudo com músicos de violino e viola. O Mundo da Saúde, 39: 43-53.

Trelha, C. S., Carvalho, R. P., Franco S. S., Nakaoski, T., Broza, T. P., Fábio, T. L., \& Abelha, T. Z. (2004). Arte e Saúde: Frequência de sintomas musculoesqueléticos em músicos da orquestra sinfônica da Universidade Estadual de Londrina. Semina: Ciências Biológicas e da Saúde, 25: 65-72. 
Watson, A. H. (2006). What can studying musicians tell us about motor control of the hand?. Journal of Anatomy, 208: 527-542.

Zaza, C., \& Farewell, V. (1997). Musicians' playing-related musculoskeletal disorders: An examination of risk factors. American Journal of Industrial Medicine, 32: 292-300.

Recebido em: 14 mar. 2018 / Aprovado em: 12 dez. 2018

Para referenciar este texto

Pereira, E. Filho, Silva, J. R. da. (2020). Musculoskeletal disorders and risk factors in string musicians. Exacta, 18(1), 16-36. https://doi.org/10.5585/Exacta.v18n1.8885. 